\title{
Longitudinal echocardiographic and clinical follow-up of patients undergoing mitral valve surgery without concomitant tricuspid valve repair
}

\author{
R. Jansen ${ }^{1}$ B. R. van Klarenbosch ${ }^{1}$ - M. J. Cramer ${ }^{1}$ R. C. A. Meijer ${ }^{2}$ P. H. M. Westendorp ${ }^{3}$ H. W. J. Meijburg ${ }^{4}$ \\ J. J. J. Bucx ${ }^{5}$ S. A. J. Chamuleau' • J. Kluin 6
}

Published online: 1 October 2018

(c) The Author(s) 2018

\begin{abstract}
Background In patients with mild to moderate functional tricuspid regurgitation (TR) and absence of right ventricular dysfunction or tricuspid annulus (TA) dilatation, there is currently no indication for concomitant tricuspid valve (TV) repair during elective mitral valve (MV) surgery. However, long-term results are conflicting. Here, we sought to determine the clinical outcome of this cohort, the rate of TR progression after MV surgery and the role of MV aetiology.

Methods Patients for elective MV surgery without concomitant TV repair were retrospectively analysed with longitudinal echocardiographic and clinical follow-up, focusing on TR progression and MV aetiology. Linear regression analysis was performed for change in TR at follow-up, using pre-determined variables and confounders.

Results In total 204 patients without TV repair were analysed. Development of more than moderate TR after a median of 3.1 [1.6-4.6] years was rarely seen: only in 2 out of 161 patients (1.2\%) with known TR grade at follow-up. Overall, median preoperative and late postoperative TR grade were equal $(p=0.116)$. Subanalysis showed no significant difference in MV aetiology subgroups. Preoperative TR grade and male gender were inversely correlated to change in TR. Mortality was not influenced by the 1-year postoperative TR severity.

Conclusion Our data showed that in a study population of patients with mild to moderate TR undergoing MV surgery without concomitant TV repair, significant late TR was rarely seen. Based on our study, it is safe to waive concomitant TV repair in this specific patient cohort.
\end{abstract}

Keywords Tricuspid valve repair · Functional tricuspid regurgitation · Mitral valve surgery $\cdot$ Mitral valve aetiology

\section{What's new}

- Guidelines recommend concomitant tricuspid valve (TV) repair for severe tricuspid regurgitation (TR); however, less is known regarding the management of mild to moderate TR.
- Our study showed that in patients with moderate TR or less, undergoing mitral valve (MV) surgery without concomitant TV repair, significant late functional TR was seldom seen, and change in TR severity was not influenced by the MV aetiology.
The Authors R. Jansen and B.R. van Klarenbosch contributed equally to the manuscript.

\section{Electronic supplementary material The online version of this} article (https://doi.org/10.1007/s12471-018-1159-4) contains supplementary material, which is available to authorized users.

S. A. J. Chamuleau

s.a.j.chamuleau@umcutrecht.nl

1 Department of Cardiology, University Medical Center Utrecht, Utrecht, The Netherlands
2 Department of Cardiothoracic Surgery, University Medical Center Utrecht, Utrecht, The Netherlands

3 Department of Cardiology, Beatrix Hospital Gorinchem, Gorinchem, The Netherlands

4 Department of Cardiology, Jeroen Bosch Hospital 's-Hertogenbosch, 's-Hertogenbosch, The Netherlands

5 Department of Cardiology, Diakonessenhuis Utrecht, Utrecht, The Netherlands

6 Department of Cardiothoracic Surgery, Academic Medical Center Amsterdam, Amsterdam, The Netherlands 
- Clinical decision-making regarding concomitant TV repair during MV surgery can be safely based on the preoperative evaluation of TR grade: it is safe to waive concomitant TV repair in our specific patient cohort.

\section{Introduction}

Mitral valve (MV) disease represents an increasing health burden, due to ageing and population growth [1]. Approximately $30-50 \%$ of patients with severe mitral regurgitation (MR) have significant tricuspid regurgitation (TR) [2]. Functional TR carries an adverse prognosis which is related to its severity [3]. It was historically believed that TR may improve after correction of the MV pathology [4]. However, recent data have shown an increase in TR in a still unclassified subgroup, irrespective of residual or recurrence of MV disease or preoperative TR [5-8]. Reoperation may be associated with high mortality [9]. Therefore, guidelines recommend concomitant tricuspid valve (TV) repair for severe TR (class I), as it improves mortality and morbidity in these patients [10-12]. However, less is known regarding the management of mild to moderate TR. Recent guidelines recommend concomitant tricuspid annuloplasty for a tricuspid annulus (TA) diameter of $\geq 40 \mathrm{~mm}$ or $>21 \mathrm{~mm} / \mathrm{m}^{2}$ (class IIa) regardless of the TR severity, solely based on expert opinion [10, 11, 13-15]. While concomitant TV repair has proven to be a safe procedure [14, 16-18], it seems severely underutilised in daily practice [12, 18-20]. Insight into the longitudinal echocardiographic and clinical follow-up, including identification of risk factors for TR progression, is of importance to evaluate and complement current guidelines.

The purpose of this study was to evaluate the echocardiographic and clinical results in patients with moderate TR or less, undergoing MV surgery without concomitant TV repair, in order to: (1) analyse postoperative TR progression and clinical outcome, and (2) evaluate the role of MV aetiology as potential risk factor for postoperative TR progression.

\section{Methods}

\section{Study population}

Between 2006 and 2014 a total of 1,226 patients underwent MV surgery in the University Medical Center Utrecht (UMCU), the Netherlands (Fig. 1). We analysed the two-dimensional (2D) transthoracic echocardiograms (TTE) and clinical data of 204 patients meeting the inclusion criteria: (1) age $\geq 18$ years; (2) preoperative TR grade $<3$; (3) referred for elective MV surgery with or without coronary artery bypass grafting and no concomitant TV repair or other concomitant procedures (e.g. MAZE or aortic valve surgery); and (4) follow-up in a participating centre. Our study was approved by the institutional review board of the UMCU, which waived patient consent.

\section{Data collection}

Preoperative and perioperative information was retrieved from the surgical database of the UMCU. Postoperative follow-up data and echocardiographic images and/or reports were obtained from the treating physician. Re-evaluation of the images was performed off-line using Xcelera software (Philips Healthcare, the Netherlands). The routine evaluation of echocardiograms was performed by experienced sonographers. Echocardiographic measurements were obtained in accordance with the guidelines [21, 22]. Left ventricular (LV) and right ventricular (RV) function, and atrial and ventricular dimensions were qualified and, if possible, quantified. The severity of valvular disease was graded $0-4$ (including grade 0.5 for trace severity) by a cardiologist of the participating centre with a special interest in cardiac imaging, using an integrative approach based on the echocardiographic criteria as recommended by the European guidelines $[10,21]$. For data analysis TR grade was divided into four groups: none, trace or mild, moderate, and more than moderate TR. Additionally the change in TR grade between the preoperative and most recent TTE was determined. In case of insufficient data regarding TR grade and TA dimensions, the images were re-evaluated in the apical 4-chamber view. TA was considered dilated when $\geq 40 \mathrm{~mm}$ [21]. Each patient was allocated to either the organic or functional MV subgroup: organic when a specific component of the MV apparatus was diseased, or functional when caused by secondary changes induced by abnormal ventricular size and leaflet retraction.

\section{Statistical analysis}

Statistical analysis was done using SPSS (version 21.0, IBM Corporation, New York). Continuous variables were expressed as mean $( \pm \mathrm{SD})$ and compared using Student's t-test in case of normally distributed data, or expressed as median (interquartile range) and compared using Wilcoxon signed-rank test or Mann-Whitney U test for non-normal distribution. One-way ANOVA or Kruskal-Wallis was used to compare $>2$ unpaired groups. Categorical data were described using frequencies and percentages. We performed comparative evaluations via the $\chi^{2}$ or McNemar's test for binary results, and $\chi^{2}$ or Wilcoxon signed-rank test in case of ordinal data. The Kaplan-Meier method was used to calculate long-term survival for the different grades of 1-year postoperative TR. Statistical significances between the sur- 
Fig. 1 Study flowchart ( $M V$ mitral valve, $U M C$ University Medical Center, $T V$ tricuspid valve, $C A B G$ coronary artery bypass grafting, $T R$ tricuspid regurgitation, TTE transthoracic echocardiography, * excluding concomitant TV repair)

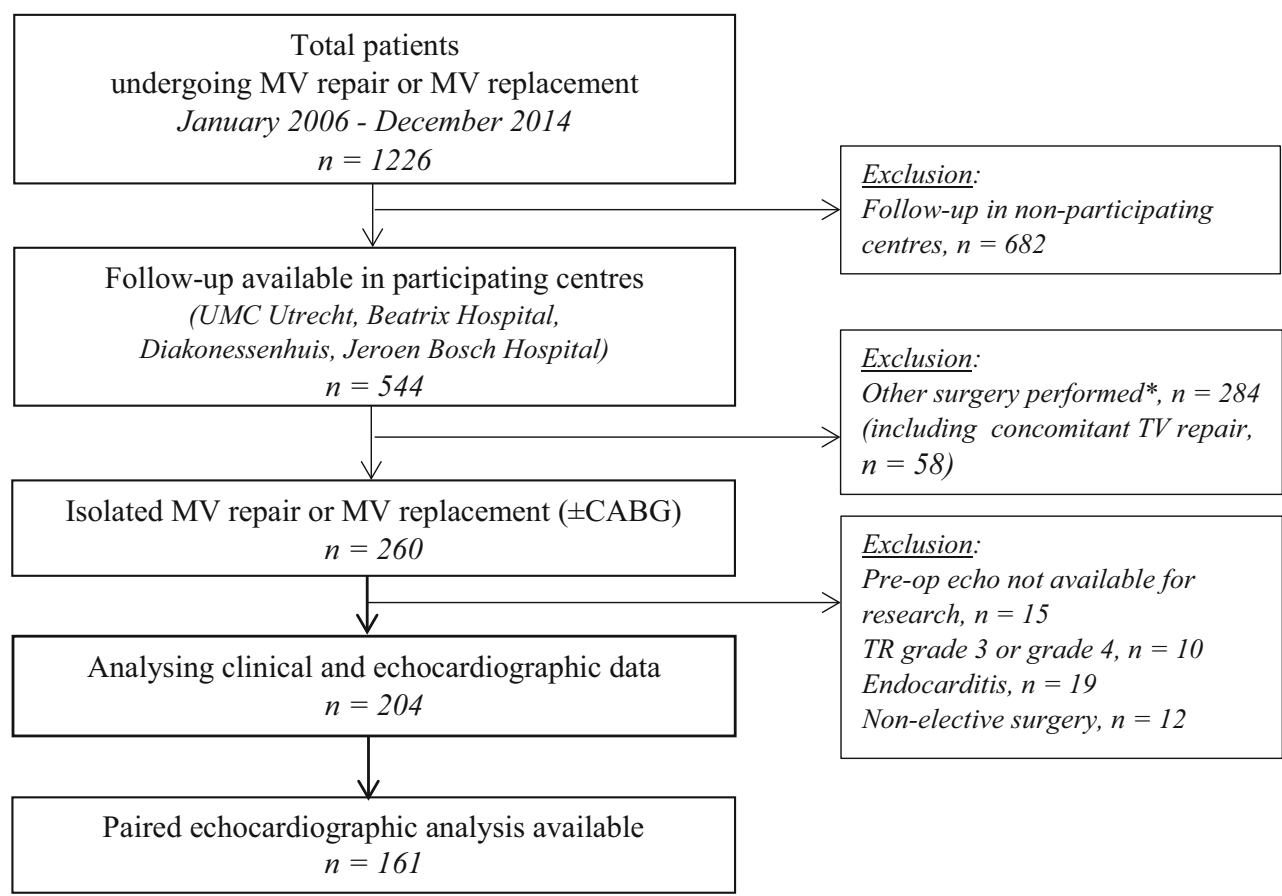

vival curves was determined by a log-rank test; the $p$-value $<0.05$ was considered statistically significant. Ordinal regression analysis for change in TR grade (between preoperative and most recent TTE) was performed based on complete case analysis, including univariable and multivariable ordinal regression on pre-determined variables of interest at baseline (MR grade, MV aetiology, MV aetiology subcategories, TR grade, TA diameter, RV function, RA dilatation, $\mathrm{LV}$ function, LA dilatation and gender) and potential confounders (age, NYHA class, pacemaker implantation and atrial fibrillation).

\section{Results}

\section{Patient characteristics}

Baseline characteristics are shown in Table 1. In Online Resource 1 (Supplementary material) the subcategories per MV aetiology are depicted. Patients with functional MV disease $(30.4 \%)$ were significantly older compared with the organic subgroup (69.6\%). Also NYHA class, EuroSCORE and rates of the comorbidities hypertension, chronic obstructive pulmonary disease, known coronary artery disease, diabetes, and renal failure were significantly higher in the functional aetiology subgroup, particularly for ischaemic MR. Preoperative MV annulus dilation was present in $58.5 \%$ of patients with organic and $>90 \%$ of patients with functional valve disease. Clinically important mitral stenosis (MS) was only seen in the organic subgroup (9.9\%). MV repair was more often performed in patients with functional disease $(96.8 \%)$, compared with $18.3 \% \mathrm{MV}$ replacement in the organic aetiology subgroup (mainly for rheumatic disease or severe calcifications). Patients with more preoperative TR showed a higher NYHA class $(p=0.011)$. Regarding the surgical characteristics, more MV replacements were performed in patients with moderate TR at baseline compared with lower grades $(p=0.017)$. Standard median sternotomy was performed in $98.5 \%$. Three patients underwent a right anterior thoracotomy. Access to the MV was achieved through a left atriotomy.

\section{Clinical results}

Clinical outcomes are depicted in Table 2. Of the 204 patients, $5(2.5 \%)$ died within 30 days (shock $n=3$, respiratory failure $n=1$, acute neoplastic disease $n=1$ ). All had ischaemic MR. Reoperation <30 days after surgery occurred in $9.3 \%$, mainly for bleeding complications (7.8\%). Of the patients with postoperative AF, this rhythm was already present at baseline in $29.8 \%$. The prevalence of AF at follow-up was similar to baseline, whereas the NYHA class $\geq$ III significantly decreased. The overall survival after a median follow-up of 5.5 [3.7-8.1] years was 87.3\%, and significantly better for the organic compared with functional MV aetiology $(92.3 \%$ versus $75.8 \%)$. The highest mortality rate was seen for ischaemic MR $(28.3 \%)$. There was no significant difference in survival according to TR grade at 1 year (Fig. 2, $p=0.972$ ). In $50 \%$ of the deceased patients 
Table 1 Baseline characteristics and procedure details $(n=204)$

\begin{tabular}{|c|c|}
\hline \multicolumn{2}{|l|}{ Patient Characteristics } \\
\hline Age (years) & $61.1 \pm 13.1$ \\
\hline Male gender & $125(61.3)$ \\
\hline $\operatorname{BSA}\left(\mathrm{m}^{2}\right)$ & $2.2 \pm 0.2$ \\
\hline NYHA class $\geq$ III & $92(45.1)$ \\
\hline EuroSCORE II & $\begin{array}{c}1.4 \\
{[0.8-3.5]}\end{array}$ \\
\hline Hypertension & $63(30.9)$ \\
\hline Known coronary artery disease $(n=203)$ & $84(40.9)$ \\
\hline Diabetes & $23(11.3)$ \\
\hline COPD & $18(8.8)$ \\
\hline Renal failure & $38(18.6)$ \\
\hline Atrial fibrillation & $38(18.6)$ \\
\hline Pacemaker or ICD & $8(3.9)$ \\
\hline \multicolumn{2}{|l|}{ Surgical Characteristics } \\
\hline Organic MV disease & $142(69.6)$ \\
\hline - Myxomatous degeneration & $79(38.7)$ \\
\hline - Fibroelastic degeneration & $47(23.0)$ \\
\hline - Rheumatic disease & $13(6.4)$ \\
\hline - Other & $3(1.5)$ \\
\hline Functional MV disease & $62(30.4)$ \\
\hline - Ischaemic cardiomyopathy & $46(22.5)$ \\
\hline - Other & $16(7.8)$ \\
\hline \multicolumn{2}{|l|}{ Preoperative MR $(n=203)$} \\
\hline$>$ Moderate & $164(80.2)$ \\
\hline \multicolumn{2}{|l|}{ Preoperative TR } \\
\hline- No & $29(14.2)$ \\
\hline - Trace or mild & $126(61.8)$ \\
\hline - Moderate & $49(24.0)$ \\
\hline$>$ Moderate & $0(0.0)$ \\
\hline Preoperative TA $\geq 40 \mathrm{~mm}(n=165)$ & $14(8.5)$ \\
\hline Preoperative TA diameter $(\mathrm{mm})(n=165)$ & $33 \pm 4$ \\
\hline MV replacement & $28(13.7)$ \\
\hline - Mechanical & $17(8.3)$ \\
\hline - Bioprosthesis & $11(5.4)$ \\
\hline MV repair & $176(86.3)$ \\
\hline - Physio ring & $137(67.2)$ \\
\hline - Cosgrove band & $38(18.6)$ \\
\hline Elevated RVSP $(n=118)$ & $51(43.2)$ \\
\hline Concomitant CABG & $75(36.8)$ \\
\hline Cross-clamp time (minutes) & $\begin{array}{l}118 \\
{[92-149]}\end{array}$ \\
\hline
\end{tabular}

Data are depicted as $n(\%)$, mean $\pm \mathrm{SD}$ or median [interquartile range]

BSA body surface area, NYHA New York Heart Association, $C O P D$ chronic obstructive pulmonary disease, ICD implantable cardioverter-defibrillator, $M V$ mitral valve, $M R$ mitral regurgitation, $T R$ tricuspid regurgitation, $T A$ tricuspid annulus, $R V S P$ right ventricular systolic pressure, $C A B G$ coronary artery bypass crafting
TR was never severe and therefore not a cause of mortality; the TR grade was unknown in the remaining subjects.

\section{Echocardiographic results}

Overall echocardiographic results at follow-up are shown in Table 2. In 204 patients echocardiographic data were available at baseline. Postoperatively, the TTE was available in 202 patients ( 2 subjects passed away), while TR grade could be determined in 161 patients using the echocardiographic data or images (78.9\%). Fig. 3 shows the overall change, including median changes per baseline TR grade subgroups. In general, almost all patients with no TR at baseline developed some TR at late follow-up, whereas in subjects with preoperatively moderate TR an increase was never seen. Overall change in TR severity was limited and not significant: in only 3 out of 161 patients (1.9\%) was a change in TR severity of $>1$ grade seen, whereas TR severity did not change in 86 patients (53.4\%). RV systolic function as measured by tricuspid annular plane systolic excursion (TAPSE) decreased from $2.4 \pm 0.5 \mathrm{~cm}$ preoperatively to $1.8 \pm 0.5 \mathrm{~cm}(p<0.001)$ at late follow-up. Medians of TR grade were similar amongst the MV aetiology groups (Table 3). Long-term follow-up showed 2 patients with TR grade $\geq 3$ (Fig. 4); one in each of the MV aetiology subgroups. Median changes in TR grade were never significant over time in either the MV aetiology subgroup or the MV aetiology subcategories (Fig. 4). Baseline MR severity was significantly lower in the functional compared with the organic group (median 3.0 versus 4.0 respectively). Both preoperative and postoperative LV and RV function were poorer in functional MV disease.

\section{Regression analysis}

Univariable regression analysis (Online Resource 2, supplementary material) showed a significant, negative correlation between change in TR grade and TR severity, TA diameter at baseline, and LA dilatation (regression coefficient $(\mathrm{r})=-2.774, p<0.0001, r=-0.839, p=0.021$, and $r=-0.276, p=0.024$ respectively). In a multivariable regression model correcting for other parameters and confounders, only baseline TR grade and male gender remained independently correlated $(r=-2.908, p<0.0001$ and $r=-0.710, p=0.027$ respectively), suggesting more improvement of TR in patients with higher TR grade preoperatively, and more improvement in males compared with females. 
Table 2 Clinical results at follow-up and echocardiographic characteristic at most recent follow-up

\begin{tabular}{|c|c|}
\hline \multicolumn{2}{|l|}{ Clinical Characteristics } \\
\hline \multicolumn{2}{|l|}{ Early outcome } \\
\hline Operative mortality & $0(0.0)$ \\
\hline 30 days mortality & $5(2.5)$ \\
\hline New permanent pacemaker or ICD & $5(2.5)$ \\
\hline Atrial fibrillation & $104(51)$ \\
\hline Reoperation & $19(9.3)$ \\
\hline - due to bleeding & $16(7.8)$ \\
\hline - other & $3(1.5)$ \\
\hline \multicolumn{2}{|l|}{ Late outcome } \\
\hline Postoperative (for most recent FU analysis) (years) & $\begin{array}{c}3.4 \\
{[1.8-5.2]}\end{array}$ \\
\hline Postoperative (for survival analysis) (years) & $\begin{array}{c}5.5 \\
{[3.7-8.1]}\end{array}$ \\
\hline Mortality & $26(12.7)$ \\
\hline - Cardiovascular & $20(9.8)$ \\
\hline - Other & $6(2.9)$ \\
\hline NYHA class $\geq \operatorname{III}(n=184)$ & $12(6.5)$ \\
\hline New reoperation $(n=184)$ & $7(3.8)$ \\
\hline - Due to mitral stenosis post MV surgery & $1(0.5)$ \\
\hline - Due to endocarditis & $2(1.0)$ \\
\hline - Due to bleeding & $1(0.5)$ \\
\hline Rehospitalisation $(n=187)$ & $66(35.3)$ \\
\hline - Cardiovascular & $46(22.5)$ \\
\hline Congestive heart failure $(n=183)$ & $19(10.4)$ \\
\hline New permanent pacemaker or ICD $(n=185)$ & $14(7.6)$ \\
\hline Atrial fibrillation $(n=183)$ & $38(20.8)$ \\
\hline OAC $(n=180)$ & $78(43.3)$ \\
\hline Stroke $(n=191)$ & $2(1.0)$ \\
\hline
\end{tabular}

\section{Discussion}

Our study of patients with moderate TR or less, undergoing MV surgery without concomitant TV repair, revealed three important findings. First, more than moderate late functional TR was seldom seen in this cohort at a median followup of 3.1 years. Secondly, overall change in TR severity was not significant when comparing the preoperative and late postoperative TR grade. Lastly, change in TR severity was not influenced by MV aetiology. Therefore our data suggest that clinical decision-making regarding concomitant TV repair during MV surgery in patients with moderate TR or less, can be safely based on the preoperative evaluation of TR grade.

\section{Prevalence and change of TR}

Several factors contribute to TR in MV disease. First, an increase in LA pressure may result in pulmonary hypertension and subsequent RV enlargement, remodelling and dysfunction. Consequently, the TA diameter increases, leading to
Table 2 (Continued)

\begin{tabular}{|c|c|}
\hline \multicolumn{2}{|l|}{ Echocardiographic Characteristics } \\
\hline Time after surgery, years $(n=164)$ & $\begin{array}{c}3.1 \\
{[1.6-4.6]}\end{array}$ \\
\hline \multicolumn{2}{|l|}{ LV function, $n(\%)(n=160)$} \\
\hline - Poor $(\mathrm{EF}<30 \%)$ or moderate $(\mathrm{EF} 30-44 \%)$ & $33(20.6)$ \\
\hline $\mathrm{LV} \mathrm{EF}, \% \pm \mathrm{SD}(n=103)$ & $55 \pm 15$ \\
\hline \multicolumn{2}{|l|}{ LA dilatation, $n(\%)(n=135)$} \\
\hline - Moderate or severe & $34(25.2)$ \\
\hline \multicolumn{2}{|l|}{ RA dilatation, $n(\%)(n=155)$} \\
\hline - Moderate or severe & $11(7.1)$ \\
\hline \multicolumn{2}{|l|}{ RV function, $n(\%)(n=147)$} \\
\hline - Poor or moderate & $11(7.5)$ \\
\hline TAPSE, $\mathrm{cm} \pm \mathrm{SD}(n=129)$ & $1.8 \pm 0.5$ \\
\hline \multicolumn{2}{|l|}{ MR grade, $n(\%)(n=159)$} \\
\hline$>$ Moderate & $3(1.9)$ \\
\hline \multicolumn{2}{|l|}{ TR grade, $n(\%)(n=161)$} \\
\hline- No & $24(14.9)$ \\
\hline - Trace or mild & $107(66.5)$ \\
\hline - Moderate & $28(17.4)$ \\
\hline$>$ Moderate & $2(1.2)$ \\
\hline $\mathrm{TA} \geq 40 \mathrm{~mm}, n(\%)(n=154)$ & $23(14.9)$ \\
\hline - Of whom had pre-operative $\mathrm{TA} \geq 40 \mathrm{~mm}$ & $3(13.0)$ \\
\hline Elevated RVSP, $n(\%)(n=97)$ & $14(14.4)$ \\
\hline \multicolumn{2}{|c|}{$\begin{array}{l}\text { Data are depicted as } n(\%) \text {, mean } \pm \mathrm{SD} \text { or median [interquartile } \\
\text { range] } \\
I C D \text { implantable cardioverter-defibrillator, } N Y H A \text { New York Heart } \\
\text { Association, } M R \text { mitral regurgitation, } O A C \text { oral anticoagulation, } \\
L V \text { left ventricular, } E F \text { ejection fraction, } L A \text { left atrial, } R A \text { right atrial, } \\
T A P S E \text { tricuspid annular plane systolic excursion, } T R \text { tricuspid } \\
\text { regurgitation, } T A \text { tricuspid annulus, } R V S P \text { right ventricular systolic } \\
\text { pressure. }\end{array}$} \\
\hline
\end{tabular}
pressure.

leaflet tethering and/or papillary muscle displacement [23]. Second, MV disease may induce AF resulting in TR. Lastly, the TV may be affected by the same disease process as the MV aetiology leading to MR. In our study, only 2 (1.2\%) patients developed more than moderate TR, in contrast with previous data showing a late significant TR prevalence ranging from $8-74 \%[6,8,14,24-26]$. A possible explanation for the non-significant change and therefore low prevalence of TR grade $\geq 3$ in our cohort is the frequent performance of concomitant TV repair in patients with a TA annulus $\geq 40 \mathrm{~mm}$. A proactive acquittal of the guidelines may have led to a selection bias, including less subjects with a larger TA diameter. Indeed, a brief evaluation of the TA diameter in patients: (1) without concomitant TV repair and TR grade $<3$ (current study cohort), (2) with concomitant TV repair and TR grade $<3$, and (3) with concomitant TV repair and TR grade $\geq 3$, revealed a mean of $33 \pm 4 \mathrm{~mm}, 42 \pm 4 \mathrm{~mm}$ and $46 \pm 6 \mathrm{~mm}$ respectively. Still, in 14 of the 165 patients with an available TA diameter $(8.5 \%)$, the annulus at baseline was dilated, of whom 3 also showed a dilated TA at follow-up. Additionally, differences may depend on hetero- 


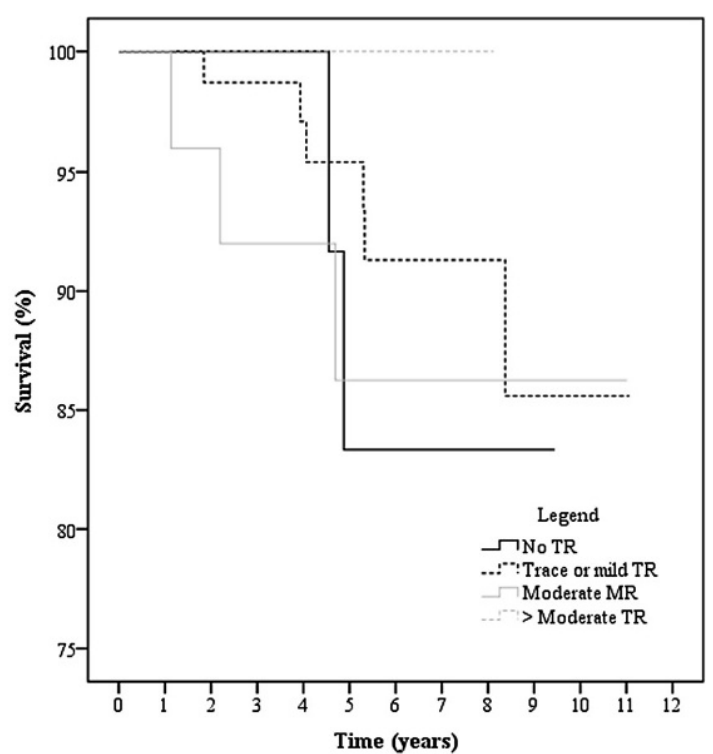

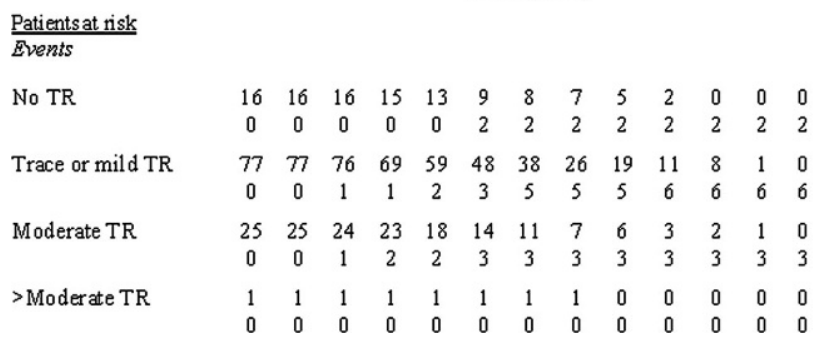

Fig. 2 Kaplan-Meier to illustrate survival according to grade of tricuspid regurgitation at 1 year postoperatively $(p=0.972)$. Number at risk and number of events are depicted

geneity in study populations and outcome definitions. Also the follow-up period to determine significant TR remains controversial. Goldstone et al. showed that late postoperative TR is a slow progressive disease, with a marked increase (grade $\geq 3$ ) after 9 years [8]. Our shorter follow-up period may therefore have led to a premature non-significant change in TR, possibly reflected by the decrease in RV systolic function (based on TAPSE) in our study population. However, other studies revealed a prevalence of significant TR (grade $>2$ ) in $48.6 \%$ and $18.2 \%$ after just 2 years [27, 28]. Lastly, our data do confirm guideline recommendations to defer concomitant TV repair in patients with non-severe TR: moderate TR at baseline decreased $(69 \%)$ or remained unchanged $(31 \%)$ in all subjects, and therefore TR never worsened. Although previous studies confirm these results [29], others have revealed TR grade $>2$ as being a risk factor for TR progression [7], possibly resulting from structural remodelling of, for example, RV and TA in patients with cardiomyopathy-related MV disease [30]. However, we expect less influence of structural remodelling on TR progression in our patient cohort, while $69.6 \%$ suffered from organic MV disease. In line with the idea of TR grade $>2$ being a risk factor, Chikwe et al. showed a higher 7-year freedom from moderate or worse
TR after concomitant TV repair compared with solely MV surgery in patients with moderate severity at baseline. On the contrary, the risk of developing moderate TR in subjects with no or mild regurgitation at baseline was low (17\% versus $15 \%$ ), matching our data. Nevertheless, their follow-up period was long ( 7 versus 3.1 years) [26]. Remarkably, our data more frequently showed a progression of TR in patients with lower baseline TR grade (probably explained by the regression toward the mean phenomenon), and female subjects [24, 29], although this was seldom significant TR and did not lead to excess mortality.

\section{MV aetiology as a potential risk factor}

Several studies have reported a high prevalence of postoperative TR in rheumatic MV [20,24] and functional MR, with rheumatic MR being reported as an independent risk factor for late significant TR [20, 24, 25, 27, 31]. Our study showed TR progression towards more than moderate in only 2 patients (1.2\%). There was no significant correlation between increased TR grade and MV aetiology, but this subanalysis was not very powerful. Differences at baseline and follow-up between the MV aetiology subgroups (e.g. lower survival and worse LV and RV function) can be explained by the poorer outcome in patients with ischaemic cardiac disease.

\section{Study limitations}

This study was retrospective with its inherent limitations. Only $17 \%$ of the 1,226 patients undergoing MV surgery in the UMC Utrecht were included. Main reasons are the exclusion of patients with follow-up in non-participating centres (682), and exclusion of patients with concomitant surgery (284). In addition, evaluation of 2D TTE in daily practice is limited by a poor imaging window, and especially TR-related measurements could not always be adequately obtained, further reducing the number of patients for clinical and echocardiographic data analysis towards 204, and for paired echocardiographic evaluation towards 161 subjects. Also standardised TR grading could not be carried out. Moreover, the surgical procedures performed in a single academic centre may not be applicable to other centres. Due to a low prevalence of late TR grade $\geq 3$ postoperatively, no analyses for this endpoint could be performed, and no risk factors for significant postoperative TR were defined. A prospective study with longer follow-up is recommended to confirm our results. 
Table 3 Echocardiographic results in patients with organic and functional mitral valve disease

\begin{tabular}{|c|c|c|c|}
\hline & $\begin{array}{l}\text { Organic } \\
(n=142)\end{array}$ & $\begin{array}{l}\text { Functional } \\
(n=62)\end{array}$ & $P$-value \\
\hline \multicolumn{4}{|l|}{ Baseline } \\
\hline \multicolumn{4}{|l|}{ LV function $(n=141 / 61)$} \\
\hline - Poor $(\mathrm{EF}<30 \%)$ or moderate $(\mathrm{EF} 30-44 \%)$ & $4(2.8)$ & $25(41.0)$ & $<0.0001$ \\
\hline \multicolumn{4}{|l|}{ LA dilatation $(n=131 / 55)$} \\
\hline - Moderate or severe & $75(57.3)$ & $27(49.1)$ & 0.060 \\
\hline \multicolumn{4}{|l|}{ RA dilatation $(n=132 / 54)$} \\
\hline - Moderate or severe & $14(10.6)$ & $6(11.1)$ & 0.940 \\
\hline \multicolumn{4}{|l|}{ RV function $(n=127 / 55)$} \\
\hline - Poor or moderate & $1(0.8)$ & $3(5.5)$ & 0.003 \\
\hline TAPSE $(\mathrm{cm})(n=87 / 43)$ & $\begin{array}{c}2.3 \\
{[2.1-2.8]}\end{array}$ & $2.0[1.8-2.5]$ & 0.001 \\
\hline \multicolumn{4}{|l|}{ MR grade $(n=141 / 62)$} \\
\hline$>$ Moderate & $122(86.5)$ & $42(67.7)$ & $<0.0001$ \\
\hline TR grade $(n=142 / 62)$ & & & 0.892 \\
\hline - No & $21(14.8)$ & $8(12.9)$ & \\
\hline - Trace or mild & $88(62.0)$ & $38(61.3)$ & \\
\hline - Moderate & $33(23.2)$ & $16(25.8)$ & \\
\hline$>$ Moderate & $0(0.0)$ & $0(0.0)$ & \\
\hline $\mathrm{TA} \geq 40 \mathrm{~mm}(n=115 / 50)$ & $8(7.0)$ & $6(12.0)$ & 0.285 \\
\hline TA diameter $(\mathrm{mm})(n=115 / 50)$ & $33 \pm 4$ & $33 \pm 5$ & 0.994 \\
\hline \multicolumn{4}{|l|}{ MOST RECENT FOLLOW-UP } \\
\hline \multicolumn{4}{|l|}{ LV function $(n=114 / 46)$} \\
\hline - Poor $(\mathrm{EF}<30 \%)$ or moderate $(\mathrm{EF} 30-44 \%)$ & $10(8.3)$ & $23(50.0)$ & $<0.0001$ \\
\hline \multicolumn{4}{|l|}{ LA dilatation $(n=94 / 41)$} \\
\hline - Moderate or severe & $23(24.5)$ & $11(26.8)$ & 0.181 \\
\hline \multicolumn{4}{|l|}{ RA dilatation $(n=109 / 46)$} \\
\hline - moderate or severe & $7(6.4)$ & $4(8.7)$ & 0.596 \\
\hline \multicolumn{4}{|l|}{ RV function $(n=105 / 42)$} \\
\hline - Poor or moderate & $3(2.9)$ & $8(19.0)$ & 0.002 \\
\hline TAPSE $(\mathrm{cm})(n=90 / 39)$ & $\begin{array}{c}1.9 \\
{[1.6-2.1]}\end{array}$ & $1.6[1.4-2.1]$ & 0.021 \\
\hline \multicolumn{4}{|l|}{ MR grade $(n=114 / 45)$} \\
\hline$>$ Moderate & $2(1.8)$ & $1(2.2)$ & 0.218 \\
\hline TR grade $(n=115 / 46)$ & & & 0.754 \\
\hline - No & $16(13.9)$ & $8(17.4)$ & \\
\hline - Trace or mild & $79(68.8)$ & $28(60.9)$ & \\
\hline - Moderate & $19(16.5)$ & 9 (19.6) & \\
\hline$>$ Moderate & $1(0.9)$ & $1(2.2)$ & \\
\hline $\mathrm{TA} \geq 40 \mathrm{~mm}(n=111 / 43)$ & $18(16.2)$ & $5(11.6)$ & 0.617 \\
\hline TA diameter $(\mathrm{mm})(n=110 / 43)$ & $34 \pm 5$ & $34 \pm 5$ & 0.869 \\
\hline Change in TR grade $(n=115 / 46)$ & & & 0.569 \\
\hline-2 & $4(3.5)$ & $2(4.3)$ & \\
\hline-1 & $23(20.0)$ & $14(30.4)$ & \\
\hline 0 & $66(57.4)$ & $20(43.5)$ & \\
\hline 1 & $20(17.4)$ & 9 (19.6) & \\
\hline 2 & $2(1.7)$ & $1(2.2)$ & \\
\hline
\end{tabular}

Data are depicted as $n(\%)$, mean $\pm \mathrm{SD}$ or median [interquartile range]

$E F$ ejection fraction, $L V$ left ventricular, $L A$ left atrial, $R A$ right atrial, $R V$ right ventricular, TAPSE tricuspid annular plane systolic excursion, $M R$ mitral regurgitation, $T R$ tricuspid regurgitation, $T A$ tricuspid annulus, $R V S P$ right ventricular systolic pressure. 

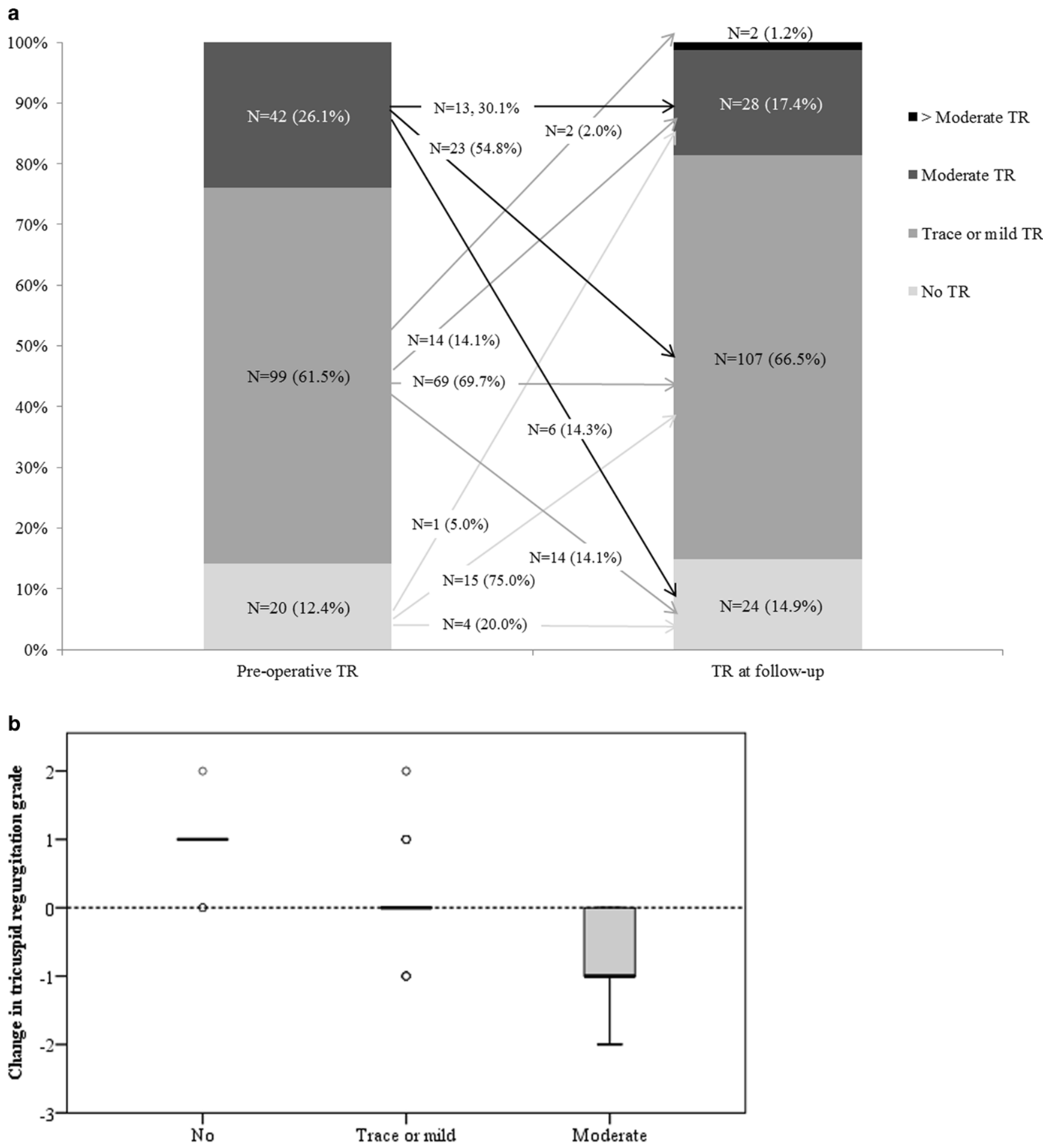

Tricuspid regurgitation grade at baseline

Fig. 3 Grade of tricuspid regurgitation (a), and change in severity per grade at baseline (b) in patients with known tricuspid regurgitation severity at both baseline and most recent follow-up echocardiogram $(n=161, T R$ tricuspid regurgitation). a Median (IQR) tricuspid regurgitation grade at baseline: 1.0 (1.0-2.0), and most recent follow-up: $1.0(1.0-1.0), p=0.166$. b Median (IQR) change in patients with no tricuspid regurgitation at baseline: $1.0(1.0-1.0)$, mild or trace tricuspid regurgitation at baseline: $0.0(0.0-0.0)$, and moderate tricuspid regurgitation at baseline: $-1.0(-1.0-$ $-1.0), p<0.0001$ 
Fig. 4 Change in grade of tricuspid regurgitation per mitral valve aetiology subcategory (Median (IQR) change in myxomatous degeneration: 0.0 $(-0.8-0.0)$, fibroelastic degeneration: $0.0(0.0-0.0)$, rheumatic disease: $0.0(-1.0-0.0)$, organic other cause: $0.0(-1.0-\mathrm{NA})$, functional ischaemic cardiomyopathy: $0.0(-1.0-1.0)$, functional other cause: 0.0 $(-0.3-0.0), p=0.575)$

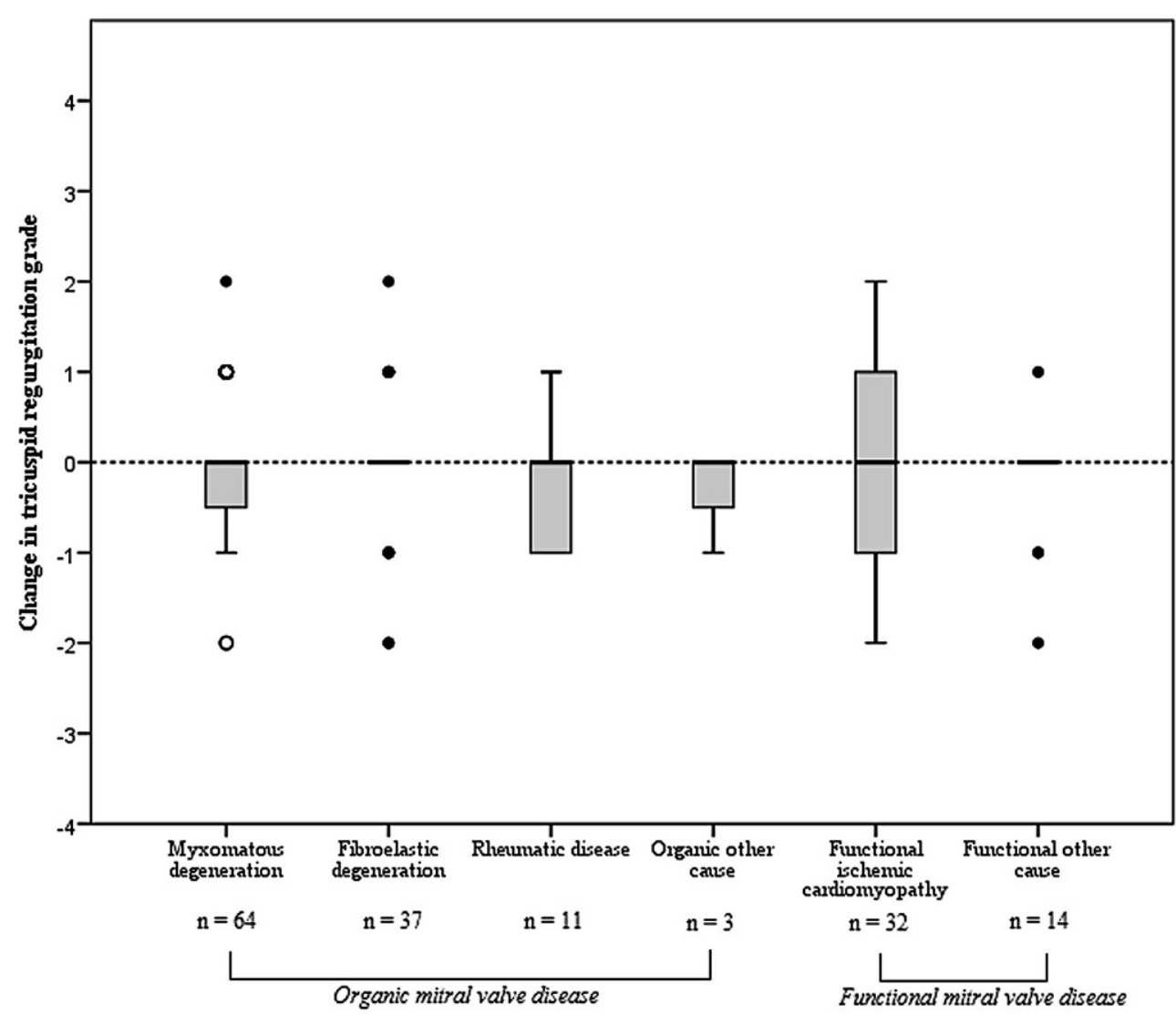

Mitral valve etiology subcategories

\section{Conclusion}

In patients with mild to moderate TR who underwent elective MV surgery without concomitant TV repair, our study showed that significant late functional TR was seldom seen. Change in TR severity in the late postoperative period was not influenced by the MV aetiology, and mortality was not correlated to 1-year postoperative TR severity. According to our study, it is safe to waive concomitant $\mathrm{TV}$ repair in this specific patient cohort, which is relevant for clinical decision-making in the heart team.

Open Access This article is distributed under the terms of the Creative Commons Attribution 4.0 International License (http:// creativecommons.org/licenses/by/4.0/), which permits unrestricted use, distribution, and reproduction in any medium, provided you give appropriate credit to the original author(s) and the source, provide a link to the Creative Commons license, and indicate if changes were made.

\section{References}

1. Nkomo VT, Gardin JM, Skelton TN, Gottdiener JS, Scott CG, Enriquez-Sarano M. Burden of valvular heart diseases: a populationbased study. Lancet. 2006;368:1005-11.
2. Cohen SR, Sell JE, McIntosh CL, Clark RE. Tricuspid regurgitation in patients with acquired, chronic, pure mitral regurgitation. I. Prevalence, diagnosis, and comparison of preoperative clinical and hemodynamic features in patients with and without tricuspid regurgitation. J Thorac Cardiovasc Surg. 1987;94:481-7.

3. Nath J, Foster E, Heidenreich PA. Impact of tricuspid regurgitation on long-term survival. J Am Coll Cardiol. 2004;43:405-9.

4. Braunwald NS, Ross J Jr., Morrow AG. Conservative management of tricuspid regurgitation in patients undergoing mitral valve replacement. Circulation. 1967;35:I63-I9.

5. Ariyoshi T, Hashizume K, Taniguchi S, et al. Which type of secondary tricuspid regurgitation accompanying mitral valve disease should be surgically treated? Ann Thorac Cardiovasc Surg. 2013;19:428-34.

6. De Bonis M, Lapenna E, Pozzoli A, et al. Mitral valve repair without repair of moderate tricuspid regurgitation. Ann Thorac Surg. 2015;100:2206-12.

7. Kwak JJ, Kim YJ, Kim MK, et al. Development of tricuspid regurgitation late after left-sided valve surgery: a single-center experience with long-term echocardiographic examinations. Am Heart J. 2008;155:732-7.

8. Goldstone AB, Howard JL, Cohen JE, et al. Natural history of coexistent tricuspid regurgitation in patients with degenerative mitral valve disease: implications for future guidelines. J Thorac Cardiovasc Surg. 2014;148:2802-9.

9. Xiao XJ, Huang HL, Zhang JF, et al. Surgical treatment of late tricuspid regurgitation after left cardiac valve replacement. Heart Lung Circ. 2004;13:65-9. 
10. Baumgartner H, Falk V, Bax JJ, et al. ESC/EACTS Guidelines for the management of valvular heart disease. Eur Heart J. 2017;38:2739-91.

11. Nishimura RA, Otto CM, Bonow RO, et al. AHA/ACC guideline for the management of patients with valvular heart disease: a report of the American College of Cardiology/American Heart Association Task Force on Practice Guidelines. J Thorac Cardiovasc Surg. 2014;148:e1-e132.

12. Desai RR, Vargas Abello LM, Klein AL, et al. Tricuspid regurgitation and right ventricular function after mitral valve surgery with or without concomitant tricuspid valve procedure. J Thorac Cardiovasc Surg. 2013;146:1126-32.

13. Dreyfus J, Durand-Viel G, Raffoul R, et al. Comparison of 2-dimensional, 3-dimensional, and surgical measurements of the tricuspid annulus size: clinical implications. Circ Cardiovasc Imaging. 2015;8:e3241.

14. Dreyfus GD, Corbi PJ, Chan KM, Bahrami T. Secondary tricuspid regurgitation or dilatation: which should be the criteria for surgical repair? Ann Thorac Surg. 2005;79:127-32.

15. van de Veire NR, Braun J, Delgado V, et al. Tricuspid annuloplasty prevents right ventricular dilatation and progression of tricuspid regurgitation in patients with tricuspid annular dilatation undergoing mitral valve repair. J Thorac Cardiovasc Surg. 2011;141:1431-9.

16. Lee H, Sung K, Kim WS, et al. Clinical and hemodynamic influences of prophylactic tricuspid annuloplasty in mechanical mitral valve replacement. J Thorac Cardiovasc Surg. 2016;151:788-95.

17. Badhwar V, Rankin JS, He M, et al. Performing concomitant tricuspid valve repair at the time of mitral valve operations is not associated with increased operative mortality. Ann Thorac Surg. 2017;103:587-93.

18. Navia JL, Brozzi NA, Klein AL, et al. Moderate tricuspid regurgitation with left-sided degenerative heart valve disease: to repair or not to repair? Ann Thorac Surg. 2012;93:59-67.

19. Calafiore AM, Iaco AL, Romeo A, et al. Echocardiographic-based treatment of functional tricuspid regurgitation. J Thorac Cardiovasc Surg. 2011;142:308-13.

20. Kim JB, Yoo DG, Kim GS, et al. Mild-to-moderate functional tricuspid regurgitation in patients undergoing valve replacement for rheumatic mitral disease: the influence of tricuspid valve repair on clinical and echocardiographic outcomes. Heart. 2012;98:24-30.
21. Lancellotti P, Tribouilloy C, Hagendorff A, et al. Recommendations for the echocardiographic assessment of native valvular regurgitation: an executive summary from the European Association of Cardiovascular Imaging. Eur Heart J Cardiovasc Imaging. 2013;14:611-44.

22. Lang RM, Badano LP, Mor-Avi V, et al. Recommendations for cardiac chamber quantification by echocardiography in adults: an update from the American Society of Echocardiography and the European Association of Cardiovascular Imaging. Eur Heart J Cardiovasc Imaging. 2015;16:233-70.

23. Shiran A, Sagie A. Tricuspid regurgitation in mitral valve disease incidence, prognostic implications, mechanism, and management. J Am Coll Cardiol. 2009;53:401-8.

24. Song H, Kim MJ, Chung CH, et al. Factors associated with development of late significant tricuspid regurgitation after successful leftsided valve surgery. Heart. 2009;95:931-6.

25. Kitai T, Furukawa Y, Murotani K, et al. Therapeutic strategy for functional tricuspid regurgitation in patients undergoing mitral valve repair for severe mitral regurgitation. Int $\mathbf{J}$ Cardiol. 2017;227:803-7.

26. Chikwe J, Itagaki S, Anyanwu A, Adams DH. Impact of concomitant tricuspid annuloplasty on tricuspid regurgitation, right ventricular function, and pulmonary artery hypertension after repair of mitral valve prolapse. J Am Coll Cardiol. 2015;65:1931-8.

27. Matsunaga A, Duran CM. Progression of tricuspid regurgitation after repaired functional ischemic mitral regurgitation. Circulation. 2005;112:I453-I7.

28. Di Mauro M, Bivona A, Iaco AL, et al. Mitral valve surgery for functional mitral regurgitation: prognostic role of tricuspid regurgitation. Eur J Cardiothorac Surg. 2009;35:635-9.

29. Yilmaz O, Suri RM, Dearani JA, et al. Functional tricuspid regurgitation at the time of mitral valve repair for degenerative leaflet prolapse: the case for a selective approach. J Thorac Cardiovasc Surg. 2011;142:608-13.

30. Fukuda S, Gillinov AM, Song JM, et al. Echocardiographic insights into atrial and ventricular mechanisms of functional tricuspid regurgitation. Am Heart J. 2006;152:1208-14.

31. Calafiore AM, Gallina S, Iaco AL, et al. Mitral valve surgery for functional mitral regurgitation: should moderate-or-more tricuspid regurgitation be treated?A propensity score analysis. Ann Thorac Surg. 2009;87:698-703. 